\title{
Comentarios
}

\section{El nebuloso escenario de los partidos políticos}

El Salvador vivió un prolongado estado de guerra, más tarde arribó a un estado de diálogo y a otro de negociación. Sería difícil, sino imposible, encontrar a alguien que no compartiera esta afirmación. De la misma forma, en el actual escenario político, pareciera existir un consenso político básico de que El Salvador se encuentra en una etapa de redefiniciones cruciales.

Sin embargo, al menos en lo que se refiere al panorama de los partidos políticos y sus ofertas electorales, éste se muestra profundamente nebuloso. De tal forma que por encima de aquel acuerdo básico según el cual nos encontramos en una etapa de redefiniciones, lo que más bien pareciera es que estamos en un estado de indefiniciones e incertidumbres.

Al hablar de un estado de indefinición en el ámbito partidario, no nos referimos a los desplazamientos de las fuerzas politicas, todavía imprecisos y no concluyentes, en cuanto a las preferencias electorales. Ciertamente, se han dado corrimientos y recomposiciones importantes en los actores políticos. Así lo indican las últimas encuestas de opinión de la UCA y de la agencia Gallup. El paso del Partido Demócrata Cristiano (PDC) de segunda a tercera fuerza constituye una de las recomposiciones más importantes. Empero, como bien lo reflejan dichas encuestas, los indecisos continúan siendo la principal fuerza electoral del pais. Ello, por una lado, es un reflejo del nivel de legitimidad y confiabilidad de que gozan los diri- gentes políticos frente a la población y, por otro, es uno de los datos que mejor sustenta el alto margen de error que acompaña a cualquier pronóstico que pretenda hacerse a estas alturas del proceso. Con todo, no es a esta indefinición e incertidumbre frente a posibles resultados electorales a la que nos referimos.

En sí mismo, con independencia de la opinión pública, el actual escenario de los partidos políti$\cos$ y sus propuestas electorales se nos presenta atravesado por profundas indefiniciones. Ello ha ido desde su incapacidad para la concertación interna para definir a sus figuras representativas, hasta los nebulosas escenarios de las definiciones ideológicas, que en algunos casos alcanzan una total carencia de identidad.

A ningún observador mínimamente avezado podría escapársele que la tardanza en el lanzamiento de las candidaturas, especialmente para vicepresidente, obedece buenamente a las marcadas divisiones internas de cada partido, como a la escasez de figuras unificadoras. En tal situación se encuentra el Partido Demócrata Cristiano (PDC) que, si bien ha anunciado una pronta presentación de su candidato a la vicepresidencia, pasó un buen tiempo ofreciendo la vacante sin mayor éxito. En todo caso, dando por supuesto que el anuncio de la dirigencia del partido sea veraz, continúa siendo inquietante que aún no presente públicamente a su candidato para vicepresidente. 
Adicionalmente, la dirigencia demócrata cristiani sigue cargando con los malestares que le provoca el no extinto Movimiento de Rescate del PDC. Así lo muestran las declaraciones vertidas el 4 de octubre por diferentes miembros de ese movimiento, que no sólo han insistido en la ilegalidad del actual cuerpo de dirección, sino en la necesaria democratización interna del instituto político.

Si bien con menos barullo, el partido ARENA tampoco escapa a estas indefiniciones y divisiones internas. Ciertamente, al menos hasta hoy, la experiencia empresarial de su dirigencia le ha dado a ARENA la capacidad de administrar internamente sus conflictos; sin embargo, existen demasiados elementos coincidentes que permiten pensar que sus actuales problemas podrían salirse de los cauces normales de resolución. La multiplicidad de rumores sobre las figuras potencialmente vicepresidenciables, la inesperada propuesta de Enrique Borgo Bustamante -personaje virtualmente desconocido para la base social del partido - como candidato de fórmula de Calderón Sol, y el pronunciamiento público, el 21 de octubre, de un sector -a todas luces disidente - de ARENA, autodenominado Movimiento de Areneros Independientes son, entre otros, factores que apuntan con meridiana claridad a la existencia de conflictos e indefiniciones en el partido.

No sería nada extraño que todo esto sea la expresión más concreta del enfrentamiento fundamental entre el sector moderado cercano al presidente Cristiani y el ala más radical -y militarista- de la derecha que, aparentemente, se está haciendo del poder del partido tras la nominación presidencial de Calderón Sol. No es un secreto bien guardado que un sector importante del partido ARENA no sólo ha dejado de apoyar a Cristiani, sino que le es contrario. Mientras tanto, otro componente, formado básicamente por empresarios cercanos al presidente Cristiani, no está del todo conforme con la nominación presidencial de Calderón Sol. La nominación de Borgo Bustamente pretendería resolver esta inconformidad.

Otros partidos de la palestra política nacional, tampoco pueden envidiar esta situación de indefinición e incertidumbre. Todo lo contrario. El caso más patético es el del Partido de Conciliación
Nacional (PCN) que, tras un prolongado y vergonzante conflicto público (Proceso, 1993, 571, 578, 582), logró acordar la nominación de su segunda promoción de candidatos para el poder ejecutivo. Pero el problema del PCN no se agota en su zigzagueante disputa pública, motivada por la renuncia de su primer candidato presidencial, el polémico general Rafael Bustillo - polémico tanto por su responsabilidad en graves hechos violatorios de los derechos humanos, como por su vinculación con otros actos ilegales como el contrabando de armas. El problema del $\mathrm{PCN}$ va más allá y alcanza el ámbito mismo de la identidad partidaria.

El PCN es casi de nacimiento un partido sin identidad propia. En su pasado mediato no fue sino la expresión partidaria del ejército $\mathrm{y}$, en tal sentido, su identidad se encontraba fuera de sí. En su pasado reciente, más bien, se perfiló como un simple apéndice del partido ARENA. Asi lo demuestra su invariable desempeño legislativo.

El problema no ha pasado del todo desapercibido para los dirigentes que asumieron su representación tras el golpe de Estado de 1979. Ya para las elecciones presidenciales de 1989, la dirección pecenista se dio cuenta de la vaciedad de su imagen política e intentó, infructuosamente, definir una personalidad partidaria más precisa. En aquel momento, el PCN arguyó un retorno a sus supuestas raíces socialdemócratas. Sin embargo, aparte que era anticipable que sus bases no lograrían entender qué significaba ese retorno. El intento no prosperó porque no era posible retornar a un lugar donde nunca se había estado $y$, por ende, de donde nunca se había partido.

A cinco años de aquel intento, y de cara a las elecciones que se avecinan, si bien con formulaciones no del todo expresas, el problema se ha vuelto a plantear. La segunda promoción de candidatos del partido, al igual que otros miembros de la dirección, ha hablado imprecisamente de una "derecha renovada". Lo cierto es que, independientemente de lo que con ello se quiera decir, para las elecciones de 1994, si tal derecha renovada continúa con el ritmo de erosión de su caudal electoral -como ha sucedido en los comicios pasados-, corre el riesgo de convertirse más bien en 
una derecha eliminada.

Por su parte, sintonizando con la frecuencia de las indefiniciones, el FMLN también ha debido afrontar sus nada desdeñables contradicciones. El prolongado $\mathrm{y}$, sobre todo, errático proceso de elección de su candidato a vicepresidente, así como la dispersión del trabajo partidista, son muestras palpables de esto. Ciertamente, más graves han sido sus incoherencias de posición frente a temas fundamentales en el cumplimiento de los acuerdos, como lo fue en el caso de la depuración de los mandos y oficiales de la Fuerza Armada; pero ello en nada reduce el alcance de sus contradicciones actuales.

En este contexto, a la relativamente disonante fórmula presidencial -donde al igual que ARENA, el candidato a vicepresidente es virtualmente desconocido para las bases-, se ha sumado más recientemente la sorpresiva autodefinición socialdemócrata de la Expresión Renovadora del Pueblo (ERP), uno de los grupos que conforman el FMLN y que hasta hace poco se conocía como Ejército Revolucionario del Pueblo. En realidad ya existian algunos signos que hacian esperar algo como esto. Los mutuos coqueteos entre el Movimiento Nacional Revolucionario (MNR) -representante histórico de la socialdemocracia en El Salvador- y el ERP no eran del todo desconocidos.

Lo cierto es que la decisión adoptada por el ERP para cambiar sụ ropaje ideológico, antes que pluralizar la conformación del FMLN, parece responder más bien a la necesidad de abscribirse a un club internacional que no sufra el desprestigio y la falta de credibilidad que hoy por hoy arrastran los círculos marxistas. Ni que decir tiene la necesidad de contar con mayores apoyos financieros. A su vez, aunque no lo han anunciado con la pompa del ERP, personeros de la Resistencia Nacional (RN), otra de las agrupaciones que conforman el FMLN, también han señalado el carácter socialdemócrata de su orientación ideológica y, yendo aún más lejos, han asegurado que es allí donde se encuentran sus orígenes como organización. Aparentemente, todos estos movimientos son también parte del fenómeno general de desplazamiento de las fuerzas

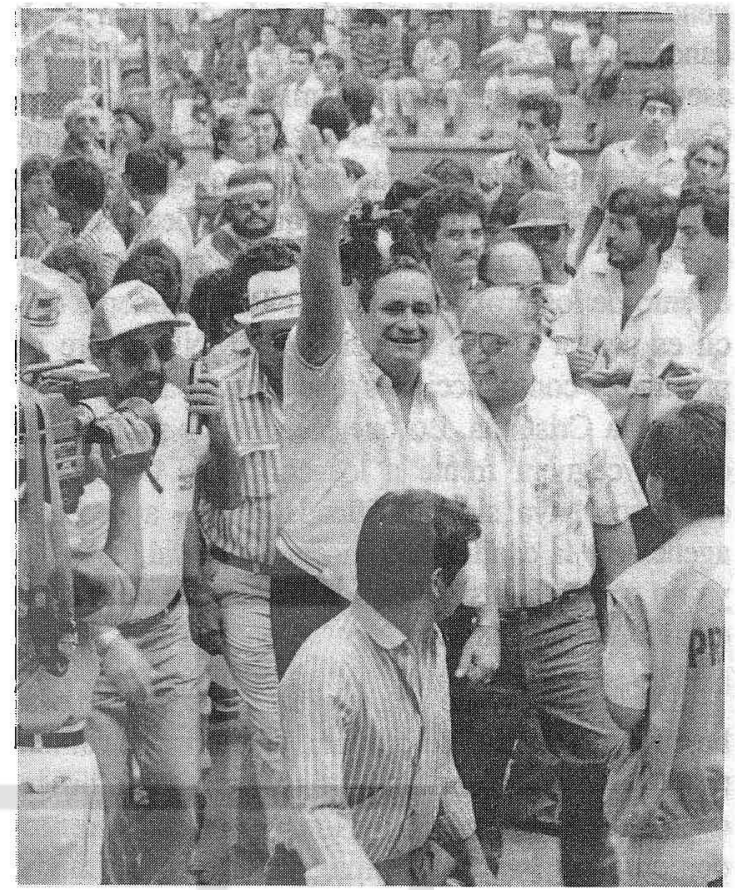

de izquierda hacia un todavia impreciso centro izquierda. En la actualidad, nadie parece estar dispuesto a ser izquierda sin más.

Hay, ciertamente, otros partidos en el escenario electoral. Ninguno de ellos se encuentra libre de contradicciones e indefiniciones. Tal es el caso del MNR, cuya fórmula presidencial jamás fue completada. El prematuro lanzamiento de su secretario general Víctor Valle como candidato presidencial no sólo constituyó una aventurada decisión de la cúpula, sino que dio muestras de lo poco ubicado que se encuentra este partido en el escenario y en la coyuntura política del pais. Por lo demás, tal lanzamiento le generó conflictos internos serios con sectores que no compartían la candidatura propuesta.

En fin, antes que nuevos pasos en materia electoral pudieran ser dados en el interior del MNR sin pensar en la necesidad de que defina una propuesta electoral minimamente decente-, la dirección del partido dio muestras de haberse lanzado a ofrecer su reducido caudal electoral y la dimisión de su candidatura presidencial, como letras de cambio para coaligarse con el PDC. Una muestra más de su escaso tino y su total despiste, exclu- 
yendo ciertamente lo referido a la dimisión de la candidatura. Por si esto fuera poco, Víctor Valle ha asegurado que su no acercamiento a la coalición Covergencia Democrática-FMLN se debe, en parte, a que ésta tiene problemas internos que el MNR no experimenta. Es difícil pensar que las declaraciones de Valle provengan de un verdadero desconocimiento de los problemas del MNR. Igualmente dificil es pensar que la dirección del MNR ignore las profundas contradicciones que atraviesan a la Democracia Cristiana. Lo que parece más probable es que la ceguera frente a los conflictos demócratacristianos haya sido justificada con la apuesta de agenciarse la candidatura vicepresidencial, cosa que ya no parece plausible de ser verdad que el PDC ha elegido ya su candidato.

De la forma que sea, el PDC, por su parte, se ha cuidado mucho de pronunciarse afirmativamente sobre la posible alianza, tan alegremente buscada y difundida por el MNR. Aparentemente, los demócrata cristianos en ningún momento estuvieron dispuestos a ceder posiciones - especialmente si se encontraba en juego la vicepresidencia- a un partido con un caudal electoral tan diminuto, como es el caso del MNR.
Otros partidos pequeños también cargan con sus propias indefiniciones e incertidumbres. Uno de ellos es el Movimiento Auténtico Cristiano (MAC) para el cual las elecciones podrían significar su desaparición definitiva del escenario político. Se encuentran también otros como los partidos de corte confesional protestante, el Movimiento Solidaridad Nacional y Pueblo Unido. De éstos se conoce menos, pero no puede esperarse mucha definición en materia de plataformas electorales. Sobre todo cuando no existe siquiera una mínima identidad ideológica partidaria.

Lo cierto es que el ámbito de los partidos político no está nada claro. Todo lo contrario, se ha constituido en un escenario bastante nebuloso. Y a esta bruma política se ha sumado el errático e incierto cumplimiento de los acuerdos de paz y de las recomendaciones de la Comisión de la verdad. Ello quizás sea propio de toda etapa de transición y redefinición. Por el momento, El Salvador se encuentra en un profundo estado de indefinición, al cual contribuye en buena medida la niebla que rodea a los partidos políticos. 